\title{
Impacto ambiental do mercúrio em lâmpadas fluorecentes descartadas no Instituto Federal de Sergipe, Campus Lagarto (Nordeste do Brasil)*
}

\author{
Pedro Lucas Ferras Ramos ${ }^{1}$, Jhennifer Laruska Leal Fraga ${ }^{1}$, Amanda \\ Santos Morais ${ }^{1}$, Lôrrana Fraga Sousa Silva ${ }^{1}$, Fernanda dos Santos \\ Morais $^{1}$, Beatriz Soares Silva1 ${ }^{1}$, Ricardo Monteiro Rocha ${ }^{2}$
}

${ }^{1}$ Instituto Federal de Sergipe. Campus Lagarto. Rodovia Lourival Batista, S/N ${ }^{\circ}$. Povoado Carro Quebrado. Lagarto-SE (CEP 49400-000).

${ }^{2}$ Instituto Federal de Sergipe. Campus Lagarto. Rodovia Lourival Batista, S/N. Povoado Carro Quebrado. Lagarto-SE (CEP 49400-000). E-mail: ricardomonteiro2003@globo.com.

Resumo. O presente artigo discorre acerca do impacto ambiental do mercúrio em lâmpadas fluorescentes descartadas no Instituto Federal de Sergipe. Desse modo, criou-se um modelo matemático para calcular a quantidade de mercúrio exposto ao ambiente proveniente de lâmpadas fluorescentes em desuso no Instituto Federal de Sergipe, Campus Lagarto, e seu impacto ambiental. Os resultados indicam que os $50.000 \mathrm{mg}$ ( $50 \mathrm{~g}$ ) iniciais de mercúrio contemplam sua totalidade de decomposição a partir do primeiro ano após o descarte. Sendo o limite de tolerância biológica de $0,000033 \mathrm{~g}$ de mercúrio por grama de creatina urinária, o mercúrio descartado no Instituto Federal de Sergipe não é somente suficiente para contaminação interna, como a expande também para uma área abrangente de contaminação externa. Observaram-se, através de questionários, que o Município de Lagarto, Estado de Sergipe, não possui pontos de coleta, indispensáveis para o cumprimento da logística reversa das lâmpadas e, por esta causa, os 1.800 alunos do Instituto Federal de Sergipe, Campus Lagarto, bem como o restante da população local, cerca de 100 mil habitantes, são obrigados à realização inadequada do descarte de lâmpadas devido à má implementação da lei instituída para a Política Nacional de Resíduos Sólidos (Lei nº 12.305/2010). (PIBIC-EM/CNPq).

Palavras-chave: Sustentabilidade; Mercúrio; Lâmpadas Fluorescentes; Logística Reversa.

Abstract. Environmental impact of mercury in fluorescent lamps discarded at the Federal Institute of Sergipe, Campus Lagarto (Northeast Brazil). This paper approaches the environmental impact of mercury in disposable fluorescent lamps in the Federal Institute of Sergipe. Thus, it was created a mathematical model to calculate the quantity of mercury exposed to the environment from non-useful fluorescent lamps in the Federal Institute of Sergipe, Campus Lagarto (Northeast Brazil), and its environmental impact. The results indicate that the first $50.000 \mathrm{mg}(50 \mathrm{~g})$ of mercury contemplate its totality of
Recebido:

$17 / 11 / 2015$

Aceito:

27/03/2016

Publicado:

30/06/2016

Acesso Aberto Artigo completo

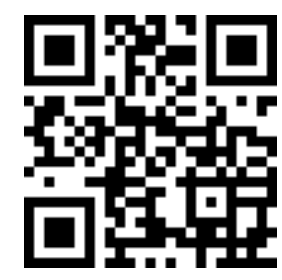

ORCIID

(1) 0000-0002-2010-3766

Pedro Lucas Ferras

Ramos

(1) 0000-0002-8158-0267

Jhennifer Laruska

Leal Fraga

(1) 0000-0003-3647-0568

Amanda Santos

Morais

(3) $0000-0003-2650-2386$

Lôrrana Fraga Sousa

Silva 
decomposition from the first year after the disposal. Being the limit of biological tolerance $0.000033 \mathrm{~g}$ of mercury per gram of urinary creatine, the disposed mercury in the Federal Institute of Sergipe is not only sufficient for the internal contamination but can also expand it for a comprehensive area of external contamination. It was observed trough questionnaires that Lagarto town, in the State of Sergipe, does not have spots of collection which are indispensable for the fulfillment of the Reverse Logistic of the lamps and, for such reason, the 1,800 students of the Federal Institute of Sergipe, Campus Lagarto, as well as all the rest of the local population, around 100,000 inhabitants, are obligated to hold inadequate disposal of lamps due to the bad implementation of the law instituted for the National Policy of Solid Waste (Federal Law no. 12,305/2010). (PIBIC-EM/CNPq).

Keywords: Sustainability; Mercury; Fluorescent lamps; Reverse logistic.

\section{Introdução}

Conceituada como um conjunto de práticas adotadas para o bom aproveitamento dos recursos e para a não poluição do meio ambiente, o termo sustentável provém do latim sustentare, no qual se designa ao sustento, apoio, conservação. Suprir as necessidades humanas atuais sem esquecer-se do conceito de sustentabilidade ambiental tem sido uma tarefa árdua. Toda e qualquer ação humana, por mínima que ela seja, finda por interferir nas suas relações interdependentes com o meio ambiente e ecossistemas, próximos ou distantes de si; por consequência correlata, impactos são desencadeados e dificilmente refreados, afetando, assim, o ambiente tal qual o humano causador primeiro.

Há a impossibilidade de resolver os crescentes e complexos problemas ambientais e reverter suas causas sem que ocorra uma mudança radical nos sistemas de conhecimento, dos valores e dos comportamentos gerados pela dinâmica de racionalidade existente, fundada no aspecto econômico do desenvolvimento (Leff, 2001).

O uso de lâmpadas fluorescentes, então, pode representar uma significativa economia doméstica, comercial e industrial. Se por um lado a natureza agradece a economia no uso dos recursos naturais pelo uso de lâmpadas fluorescentes na iluminação, a proliferação do seu uso está gerando uma nova demanda ambiental: o que fazer com as lâmpadas queimadas? O mercúrio contido nas lâmpadas, como se sabe (Zavariz e Glina, 1992; Bernhoft, 2012) pode contaminar o solo, as plantas, os animais e a água. $\mathrm{O}$ risco oferecido por uma única lâmpada é quase nulo. No entanto, levando-se em consideração que o Brasil comercializa cerca de 100 milhões de lâmpadas por ano, o problema do descarte destas se agrava enormemente (Durão Jr. e Windmöller, 2008).

O Ministério do Meio Ambiente (MMA) e entidades representativas do setor de lâmpadas fluorescentes de vapor de sódio e mercúrio e de luz mista assinaram, em Brasília, em 27/11/2014, um acordo setorial que estabelece a logística reversa desses produtos. $\mathrm{O}$ acordo prevê responsabilidade compartilhada pelo ciclo de vida dos produtos e propicia para que esses materiais, depois de usados, possam ser reaproveitados. A proposta passou por consulta pública e aprovação do Comitê orientador para a Implantação da Logística Reversa - CORI (Ribeiro e Oliveira, 2014).

De acordo com a Política Nacional de Resíduos Sólidos, instituída pela Lei ${ }^{\circ}$ 12.305/2010 (Brasil, 2010), a logística reversa pode ser definida como instrumento de desenvolvimento econômico e social caracterizado por um conjunto de ações, procedimentos e meios destinados a viabilizar a coleta e a restituição dos resíduos sólidos ao setor empresarial, para reaproveitamento, em seu ciclo ou em 
outros ciclos produtivos, ou outra destinação final ambientalmente adequada. Vale destacar que as empresas fabricantes dessas lâmpadas tornaram-se, praticamente, importadoras, o que causa uma preocupação maior, pois não existe legislação brasileira que estabeleça limites de concentração de mercúrio nas lâmpadas, portanto, sua composição ainda não é controlada (MMA, 2014).

Como método preventivo relativo às doenças diretas ou contaminações em rios ou aquíferos, faz-se necessária a ciência da quantidade de mercúrio presente em cada lâmpada fluorescente para que se possa estimar quanto está sendo descartado no ambiente. A quantidade de mercúrio em uma lâmpada fluorescente pode variar de acordo com o tipo de lâmpada, o fabricante e o ano de fabricação. Essa quantidade vem diminuindo significativamente com 0 decorrer dos anos (Durão Jr. e Windmöller, 2008). Atualmente, a quantidade média de mercúrio em uma lâmpada fluorescente de $40 \mathrm{~W}$, segundo a USEPA (United States Environmental Protection Agency) está em torno de $21 \mathrm{mg}$. Existe controvérsia quanto à quantidade das espécies de mercúrio nas lâmpadas. Dados fornecidos pela NEMA indicam que $0,2 \%$, ou seja, $0,42 \mathrm{mg}$ estão sob a forma de mercúrio elementar, no estado de vapor. Os outros 99,8\% (20,958 mg) estão sob a forma de $\mathrm{Hg}^{2}$, adsorvido sobre a camada fosforosa e o vidro (Raposo, 2001).

Mesmo sendo ubíquo no ambiente, o mercúrio é tido como uma das principais substâncias poluentes descritas por agências de proteção ambiental em todo o mundo. A Agência dos Estados Unidos para Substâncias Tóxicas e Registros de Doenças lista o mercúrio como a terceira substância mais tóxica (Guedes, 2009).

Os principais sintomas associados à toxicidade por exposição ao mercúrio incluem tremor, vertigem, entorpecimento, dor de cabeça, cãibra, fraqueza, depressão, distúrbios visuais, dispneia, tosse, inflamações gastrointestinais, queda de cabelo, náusea e vômitos (Micaroni et al., 2000). Em um estudo com pacientes expostos ao mercúrio metálico, encontraram-se dados sobre ansiedade e depressão em todos os casos, além de insônia, irritabilidade, esquecimento, dificuldade de concentração, insegurança e diminuição das habilidades sociais (Vroom e Greer, 1972).

Na superfície terrestre, o mercúrio é depositado no solo e em ambientes aquáticos. No solo, o tempo de retenção é longo, resultando em acúmulo desse elemento, o que pode acarretar seu lançamento nas águas, por meio de escoamento superficial e erosão (Tinoco et al., 2010).

No meio aquático, o mercúrio pode ser encontrado na água propriamente dita e nos sedimentos. Ao atingirem os ambientes aquáticos, as espécies inorgânicas do mercúrio podem sofrer reações mediadas, principalmente, por micro-organismos, que alteram seu estado inicial, resultando em compostos organomercuriais como o metilmercúrio, mais tóxico do que as espécies inorgânicas. O metilmercúrio é facilmente absorvido por peixes e outros animais aquáticos, o que leva à deposição dessa substância nos tecidos, acumulandose ao longo do tempo e atingindo, na cadeia biológica, concentrações bem maiores do que as encontradas nas águas e nos sedimentos (Azevedo, 2003).

$\mathrm{O}$ risco associado à utilização do mercúrio é muito alto e a grande maioria da população não está informada de procedimentos adequados de segregação e destinação. Desta forma, o mercúrio contido em materiais diversos chega a aterros não apropriados para receber resíduos perigosos e isso possibilita a contaminação difusa de solos e recursos hídricos e a assimilação deste metal pela fauna e flora (Silva, 2013).

Em fevereiro de 2003, o Conselho de Governo, do Programa das Nações Unidas para o Meio Ambiente (UNEP/PNUMA) concluiu, com base em estudos elaborados por especialistas em contaminação ambiental por mercúrio, que existem evidências suficientes e significativas dos impactos globais adversos para a saúde e para o meio ambiente causados pelo mercúrio e seus compostos, que requerem ações mundiais, nacionais, regionais e locais, recomendando que cada país 
estabeleça metas e adote medidas de redução/eliminação das fontes antropogênicas de mercúrio (Zavariz, 2007).

Os esforços para minimizar o teor nocivo do mercúrio são globais, e diversos são os estudos que priorizam práticas sustentáveis capazes de atender aos requisitos mínimos de prevenção e cuidados especiais para reduzir os efeitos provenientes de sua contaminação. Diversas pesquisas existentes comprovam a problemática e reclamam uma solução. Sendo assim, os esforços em prol da conscientização são um método indispensável para tornar os cidadãos cientes do problema em questão e, por meio da difusão de conhecimentos, incentivar ações práticas de soluções possíveis.

O Brasil consome um grande número de lâmpadas fluorescentes, o qual apresenta mercado ascendente. Mas, infelizmente após o consumo a grande maioria dessas lâmpadas é descartada inadequadamente. Por outro lado viu-se que, apesar de poucas empresas atuantes, o Brasil possui tecnologia disponível para reciclar a lâmpada fluorescente e principalmente que já há utilização dos seus subprodutos em outras cadeias produtivas. O que falta para a destinação adequada dessas lâmpadas é justamente o que a Política Nacional de Resíduos Sólidos institui como instrumento da responsabilidade compartilhada dos produtos, a logística reversa (Mourão e Seo, 2012).

Há muito se despertou a atenção social para com o elevado grau de contaminação do mercúrio e seus impactos ambientais. A Política Nacional de Resíduos Sólidos (Lei $\mathrm{n}^{\circ}$ 12.305/2010) instituiu-se como método de coleta, reaproveitamento e reposição dos resíduos ao setor empresarial. Em decorrência disso, milhares de empresas passaram a adotar 0 fluxo reverso de lâmpadas fluorescentes, atenuando a ação nociva do mercúrio no ambiente.

O presente trabalho objetiva calcular a quantidade de mercúrio exposto ao ambiente proveniente de lâmpadas fluorescentes em desuso no Instituto
Federal de Sergipe, Campus Lagarto, e seu impacto ambiental.

\section{Material e métodos}

A metodologia do trabalho foi baseada em Revisões Bibliográficas, contendo estudos acerca do mercúrio e seus impactos e efeitos no ambiente, levantamento de dados, entrevistas, pesquisas e resultados desenvolvidos por meio de informações obtidas através de visitas de campo realizadas no Instituto Federal de Sergipe, Campus Lagarto, com os responsáveis técnicos por as lâmpadas, entre os dias 7 e 24 de abril de 2015.

Para melhor análise de evidências e desenvolvimento de parâmetros sólidos, fez-se necessário um estudo de caso por meio de questionários, aplicados entre os dias 27 e 30 de abril e $1^{\circ}$ e 7 de maio de 2015, em áreas de comercialização de lâmpadas fluorescentes no Município de Lagarto, Estado de Sergipe. O procedimento propôs a avaliação acerca da aplicação efetiva da logística reversa na área em estudo. Como consequência, foi feita a identificação do problema por meio das respostas obtidas através das questões formuladas, que dizem respeito à existência ou não de pontos de coleta de lâmpadas na região, a destinação dada a essas lâmpadas e a análise da compreensão, por parte dos comerciantes, acerca das consequências de um descarte inadequado no meio ambiente.

A construção da modelagem matemática para avaliação da quantidade de Hg lançado no meio ambiente e a execução do seu modelo por meio de uma planilha no Excel foram efetuadas considerando pesquisas anteriores e conclusões, bem como os resultados advindos do acervo informacional adquirido. Tal processo perdurou durante todo o restante dos meses de abril e maio de 2015.

O modelo foi plotado em forma gráfica e avaliado por meio de discussões sobre os dados encontrados, como a quantidade de mercúrio presente em lâmpadas fluorescentes descartadas no lixo comum pelo Instituto Federal de Sergipe em relação ao tempo em meses. 


\section{Resultados e discussão}

O gráfico, gerado a partir da aplicação da modelagem matemática e plotado com o auxílio do software Microsoft Excel, está explicitado na Figura 1.

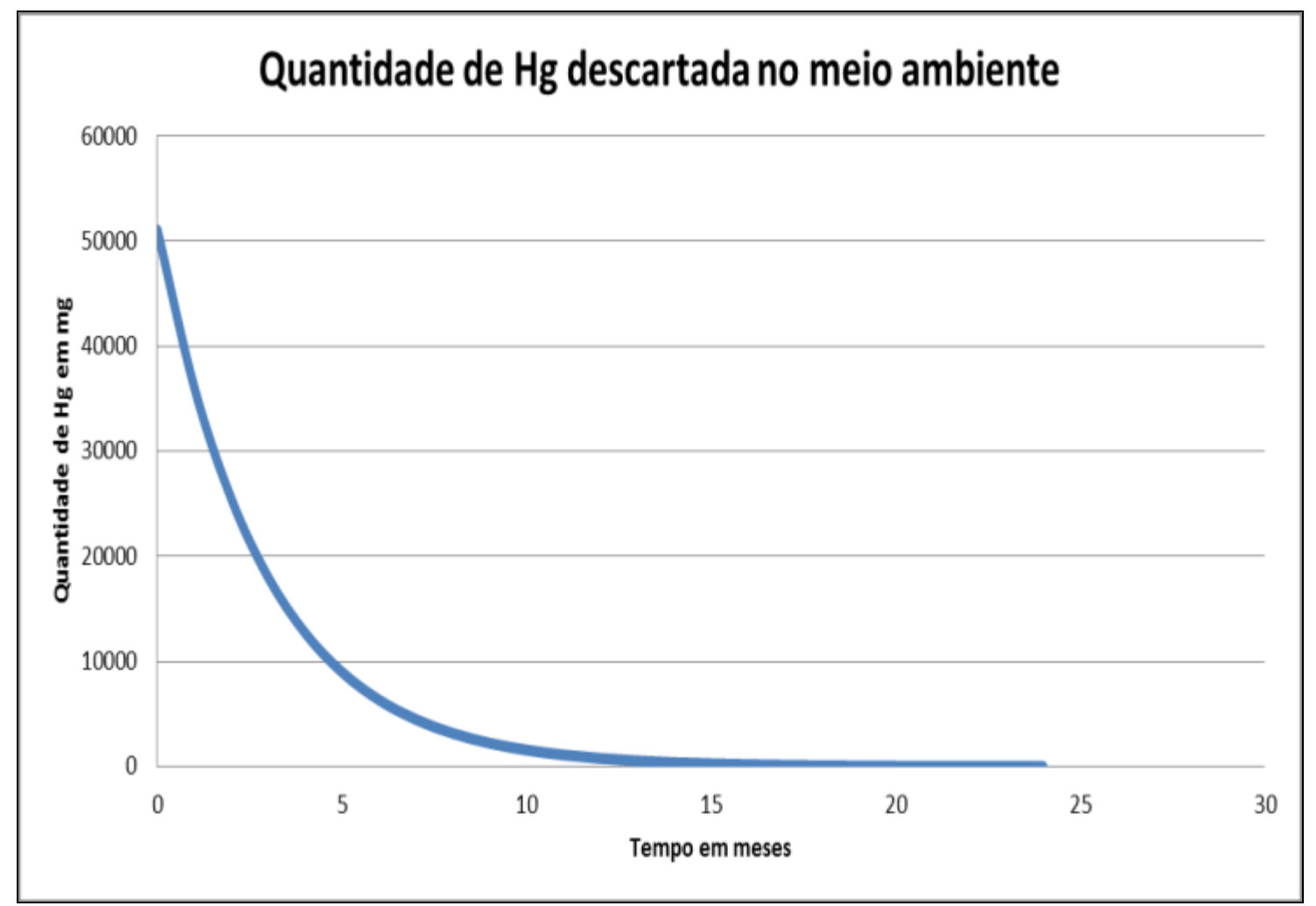

Figura 1. Gráfico da quantidade estimada de mercúrio presente em lâmpadas descartadas no lixo comum no Instituto Federal de Sergipe, Campus Lagarto, em relação ao tempo em meses.

Sabendo que a meia-vida do mercúrio é de dois meses e o limite de tolerância biológica segundo a ABNT-NBR 10004-2004 é de $33 \mu \mathrm{g}(0,000033 \mathrm{~g})$ de mercúrio por grama de creatina urinária (ABNT, 2004), o gráfico expõe uma constante à quantidade de $\mathrm{Hg}$ : o descarte contínuo das lâmpadas no lixo comum proporciona a permanência do mercúrio no meio ambiente. Os resultados dispostos no gráfico indicam que os $50.000 \mathrm{mg}$ (50 g) iniciais de mercúrio contemplam sua totalidade de decomposição a partir do primeiro ano após o descarte. O valor, além de exceder o limite de tolerância biológica, choca-se com a tendência atual de diminuição dos metais tóxicos, como a exposta pela Resolução CONAMA $n^{\circ}$
401/2008 (Brasil, 2008), que estabelece os limites máximos de chumbo, cádmio e mercúrio para pilhas e baterias comercializadas no território nacional.

A aplicação de questionários na área comercial do Município de Lagarto evidencia um agravante: as lâmpadas não recebem a destinação adequada. A má execução da lei instituída pela Política Nacional de Resíduos Sólidos é evidente. O Município não possui pontos de coleta de lâmpadas em desuso, indispensáveis para o cumprimento da Logística Reversa. O descumprimento da lei interfere no descarte adequado das lâmpadas e a inexistência de uma logística torna o lixo comum o lugar de destino desses resíduos por parte dos cerca de 100 mil habitantes do município, 
além dos 1.800 estudantes do Instituto Federal de Sergipe.

A Tabela 1 apresenta o quantitativo de lâmpadas fluorescentes utilizadas no campus, bem como a taxa de troca mensal e a quantidade média de mercúrio descartada no meio ambiente.

Tabela 1. Quantidades referentes ao uso de lâmpadas fluorescentes e o consequente descarte de mercúrio no Instituto Federal de Sergipe, Campus Lagarto.

\begin{tabular}{|l|c|}
\hline Lâmpadas utilizadas no instituto & 2.184 \\
\hline Troca média de lâmpadas mensal & 91 \\
\hline Quantidade média de Hg descartada no meio ambiente (mg) & 1.911 \\
\hline
\end{tabular}

A contaminação ocasionada por lâmpadas fluorescentes descartadas no lixo comum no campus é relevante, e o período de um ano para sua decomposição total dá margem à agregação, por parte do solo e dos lençóis freáticos subterrâneos, de parte do metal tóxico, fator causa de diversas doenças de contato direto ou indireto.

O Relatório Mercado de Mercúrio no Brasil (ACPO, 2006), elucida acerca do aparecimento do Mal de Minamata no Século XX, conjunto de sintomas e sinais de intoxicação grave derivada da exposição da população de pescadores da cidade japonesa de Minamata que, ao se alimentar de peixes e outros frutos do mar que continham elevados teores de metilmercúrio, passou a desenvolver vários sintomas. Uma fábrica de acetaldeído e de cloreto de vinila usava o mercúrio como elemento catalisador em seu processo de produção, entre 1920 e 1968. Os resíduos de mercúrio eram despejados no estuário que desembocava na Baía de Minamata. Nos anos 1960 e 1970, os médicos da região constataram um número cada vez maior de efeitos tóxicos em pessoas contaminadas, principalmente nos filhos de mães que ingeriram peixes e frutos do mar da região: ataxia, deterioração da fala, constrição do campo visual, dificuldades auditivas, alterações sensoriais, deficiência mental e paralisia mental.

Bueno et al. (2011) concluíram, a respeito da vigilância ambiental referente ao mercúrio, que determinados grupos populacionais merecem especial atenção no que se refere à exposição ao mercúrio pelo fato de possuírem maiores probabilidades de exposição a níveis perigosos do mercúrio ou, em função de serem portadoras de condições biológicas ou patológicas, poderem exacerbar os efeitos da intoxicação. Entre eles estão os trabalhadores expostos ocupacionalmente ao mercúrio; as populações vizinhas a fontes de poluição por mercúrio; as populações de regiões com contaminação por mercúrio (em especial as ribeirinhas e indígenas) que têm o pescado como fonte principal de proteínas; as gestantes, lactantes e crianças.

Segundo a Resolução CONAMA n ${ }^{\circ}$ 001/1986 (Brasil, 1986), considera-se impacto ambiental qualquer alteração das propriedades físicas, químicas e biológicas do meio ambiente, causada por qualquer forma de matéria ou energia resultante das atividades humanas que, direta ou indiretamente, afetam a saúde, a segurança e o bem-estar da população; as atividades sociais e econômicas; a biota; as condições estéticas e sanitárias do meio ambiente; e a qualidade dos recursos ambientais.

O crescente impacto da ação humana sobre o meio ambiente justifica a nocividade das consequências decorrentes, fontes de prejuízos constantes. O desassossego associado aos males ambientais provém do conhecimento sobre suas causas, majoritariamente antrópicas, e consequências, majoritariamente funestas.

Em tempos catastróficos, as preocupações relativas aos impactos ambientais ganham força descomunal. A divulgação intensiva dos acontecimentos quanto às calamidades expõe o fim lastimoso para o qual a humanidade tem se 
encaminhado. Contudo, a exposição excessiva não garante a conscientização em níveis recomendados. O distanciamento ilusório provocado pela visualização de catástrofes em locais aparentemente desligados da própria realidade cotidiana desfaz o interesse em aprender sobre práticas ambientalmente corretas.

Desta forma, os avanços científicotecnológicos, de sistemas de gestão e de legislação ambiental, somados à melhoria da educação em geral e a um aumento da consciência sobre as questões ambientais, são fundamentais para minimizar os impactos causados pela civilização humana (Costa et al., 2012). Sendo assim, aproximar determinada comunidade da degradação ambiental que ela produz, por meio de dados concretos expostos em estudos realizados na própria comunidade, compõe a relevância do tema em estudo.

\section{Conclusões}

O Município de Lagarto, onde está localizado o Instituto Federal de Sergipe, não possui pontos de coleta, indispensáveis para a destinação final adequada de lâmpadas. A aplicação da logística reversa, tal qual prevê a Política Nacional de Resíduos Sólidos (Lei n ${ }^{\circ}$ 12.305/2010), seria de suma importância para a redução da contaminação ambiental. $\mathrm{O}$ quadro torna-se ainda mais grave ao considerar-se uma abrangência maior que os 1.800 alunos do Instituto Federal de Sergipe, Campus Lagarto, local de realização do estudo, como, por exemplo, a população total do município, de 100 mil habitantes, em que, igualmente, não há pontos de coleta e reciclagem.

\section{Declaração de conflito de interesses}

Os autores declaram não haver conflito de interesses.

\section{Referências}

ABNT - Associação Brasileira de Normas Técnicas. ABNT-NBR 10004. Resíduos sólidos - Classificação. Rio de Janeiro: ABNT, 2004.
ACPO - Associação de Combate aos Poluentes. Relatório Mercado de Mercúrio no Brasil. 2006. Disponível em: <http://www.acpo.org.br/ campanhas/mercurio/relatorio_mercado_portug ues.pdf $>$. Acesso em: 23 jan. 2016.

Azevedo, F. A. Toxicologia do mercúrio. São Carlos: Rima, 2003.

Bernhoft, R. A. Mercury toxicity and treatment: a review of the literature. Journal of Environmental and Public Health, v. 2012, Article ID 460508, 2012. Disponível em: <http://dx.doi.org/10.1155/2012/460508>.

Acesso em: 19 nov. 2015.

Branches, F. J. P.; Erickson, T. B.; Aks, S. E.; Hryhorczuk, D. O. The price of gold: mercury exposure in the Amazonian rain forest. J. Toxicol. Clin. Toxicol., v. 31, p. 295-306, 1993.

Brasil. Leis, decretos, etc. Lei $\mathbf{n}^{\mathbf{0}} \mathbf{1 2 . 3 0 5}$, de 2 de agosto de 2010. Institui a Política Nacional de Resíduos Sólidos; altera a Lei n ${ }^{\circ} 9.605$, de 12 de fevereiro de 1998; e dá outras providências. Disponível em: <http://www.planalto.gov.br/ ccivil_03/_ato2007-2010/2010/lei/112305.htm>. Acesso em: 19 nov. 2015.

Brasil. Leis, decretos, etc. Resolução Conama $\mathbf{n}^{\circ}$ 001, de 23 de janeiro de 1986. Dispõe sobre critérios básicos e diretrizes gerais para a avaliação de impacto ambiental. Disponível em: $<$ http://www.mma.gov.br/port/conama/

legiabre.cfm?codlegi=23>. Acesso em: 22 jan. 2016.

Brasil. Leis, decretos, etc. Resolução Conama $n^{\circ} \mathbf{4 0 1}$, de 4 de novembro de 2008. Estabelece os limites máximos de chumbo, cádmio e mercúrio para pilhas e baterias comercializadas no território nacional e os critérios e padrões para o seu gerenciamento ambientalmente adequado, e dá outras providências. Disponível em: <http://www.mma.gov.br/port/conama/ legiabre.cfm?codlegi=589>. Acesso em: 19 nov. 2015.

Bueno, P. C.; Rodrigues, J. C.; Lemos, A. F.; Malaspina, F. G.; Matsui, C. T.; Rohlfs, D. B. Exposição humana a mercúrio: subsídios para o fortalecimento das ações de vigilância em saúde. Caderno de Saúde Coletiva, v. 19, p. 443-447, 2011. Disponível em: <http://www.iesc.ufrj.br/cadernos/images/csc/2 011_4/artigos/csc_v19n4_443-447.pdf $>$. Acesso em: 23 jan. 2016.

Canela, M. C. Determinação de mercúrio a nível de traço: aplicação em amostras de interesse ambiental. Campinas: Universidade Estadual de Campinas, 1995. (Dissertação de Mestrado). 
Costa, D. T.; Vaz, J. S.; Lopes, J. S. F.; Gotardi, A. Grandes impactos ambientais no mundo. Caderno Meio Ambiente e Sustentabilidade, v. 1, n. 1, p. 56-73, 2012. Disponível em: $<$ http://www.grupouninter.com.br/web/ revistameioambiente/index.php/ cadernomeioambiente/article/view/104/41>. Acesso em: 23 jan. 2016.

Durão Jr., W. A.; Windmöller, C. C. A questão do mercúrio em lâmpadas fluorescentes. Química Nova na Escola, v. 28, p. 15-19, 2008. Disponível em: <http://qnesc.sbq.org.br/ online/qnesc28/04-QS-4006.pdf>. Acesso em: 19 nov. 2015.

Guedes, N. C. C. Protocolo de avaliação do mercúrio potencialmente tóxico em águas naturais. Campinas: Universidade Estadual de Campinas, 2009. (Tese de doutorado).

Jardim, W. F.; Gimenez, S. M. N.; Canela, M. C.; Morais, S. G. Acute toxicity of $\mathrm{Hg}^{0}$ and $\mathrm{Hg}^{2+}$ ions to Escherichia coli. Chem. Spec. and Bioav., v. 5, p 97-100, 1993. Disponível em: <http://dx.doi.org/10.1080/09542299.1993.1108 3208 >. Acesso: 19 nov. 2015.

Leff, E. Epistemologia ambiental. São Paulo: Cortez, 2001.

Micaroni, R. C. C. M.; Bueno, M. I. M. S.; Jardim, W. F. Compostos de mercúrio. revisão de métodos de determinação, tratamento e descarte. Química Nova, v. 23, p. 487-495, 2000. Disponível em: <http://www.scielo.br/ pdf/qn/v23n4/2648.pdf>. Acesso em: 19 nov. 2015.

MMA - Ministério do Meio Ambiente. Logística Reversa. Disponível em: $<$ http://www.mma.gov.br/cidadessustentaveis/residuos-solidos/instrumentos-dapolitica-de-residuos/comite-orientador-logisticareversa>. Acesso em: 26 dez. 2014.

Mourão, R. F.; Seo, E. S. M. Logística reversa de lâmpadas fluorescentes. Revista de Saúde, Meio Ambiente e Sustentabilidade, v. 7, n. 3, p. 94-112, 2012. Disponível em: <https://www.ipen.br/biblioteca/2012/19127.pdf>. Acesso em: 26 dez. 2014.
Raposo, C. Contaminação ambiental provocada pelo descarte não controlado de lâmpadas de mercúrio no Brasil. Ouro Preto: Universidade Federal de Ouro Preto, 2001. (Tese de doutorado).

Ribeiro, R.; Oliveira, T.; Tardin, V. Logística reversa de lâmpadas tem acordo setorial assinado. Abras, 2014. Disponível em: $<$ http://www.abras.com.br/supermercadosustent avel/logistica-reversa/logistica-reversa-delampadas-tem-acordo-setorial-assinado/>. Acesso em: 26 dez. 2014.

Silva, F. R. Impactos ambientais associados à logística reversa de lâmpadas fluorescentes. Revista de Saúde, Meio Ambiente e Sustentabilidade, v. 8, p. 42-69, 2013. Disponível em: <http://www.revistas.sp.senac.br/ index.php/ITF/article/viewFile/320/302>. Acesso em: 19 nov. 2015.

Tinoco, A. A. P.; Azevedo, I. C. A. D.; Marques, E. A. G.; Mounteer, A. H.; Martins, C. P.; Nascentes, R.; Reis, E. L.; Natalino, R. Avaliação de contaminação por mercúrio em Descoberto, MG. Eng. Sanit. Ambient., v. 15, n. 4, p. 305-314, 2010. Disponível em: <http://www.scielo.br/pdf/esa/v15n4/a03v15n4. pdf $>$. Acesso em: 19 nov. 2015.

Vroom, F.; Greer, M. Mercury vapor intoxication. Brain, v. 95, p. 305-318, 1972.

Zavariz, C. Documento de recomendações a serem implementadas pelos órgãos competentes em todo o Território Nacional relativas às lâmpadas de mercúrio. São Paulo, 2007. Disponível em: <http://www.acpo.org.br/ campanhas/mercurio/docs/recomendacoes_lamp adas_hg.pdf >. Acesso em: 19 nov. 2015.

Zavariz, C.; Glina, D. M. R. Avaliação clíniconeuro-psicológica de trabalhadores expostos a mercúrio metálico em indústria de lâmpadas elétricas. Revista de Saúde Pública, v. 26, n. 5, p. 356-365, 1992. Disponível em: <http://www.scielo.br/pdf/rsp/v26n5/10.pdf>. Acesso em: 19 nov. 2015.

Informação da Licença: Este é um artigo Open Access distribuído sob os termos da Licença Creative Commons Attribution, que permite uso irrestrito, distribuição e reprodução em qualquer meio, desde que a obra original seja devidamente citada. 